A BIOLOGICAL SPORES BAIT TRAP TECHNIQUE AS A NEW APPROACH FOR TRAPPING, MONITORING AND CONTROLLING THE MEDFLIES ADULTS, Ceratitis capitata (WIEDEMANN) (DIPTERA : TEPHRITIDAE).

\author{
Sayed;M. M. El-Garhy ${ }^{1}$ and Narmen, A. Youssef ${ }^{2}$ \\ 1- Plant Protection Res. Institute Dept. of Biological Control Doki, Giza \\ Agriculture Research Center. \\ 2- Plant Protection Department, Faculty of Agriculture, Fayoum University.
}

\begin{abstract}
Laboratory and field assessments were carried out to determine the efficiency of three biological control agents Metarhisium anisopliae, Verticillium lecanii and Beauveria bassiana locally isolated from dead pupae and adults medflies Ceratitis capitata against adults of $C$. capitata. Serial dilutions were prepared at $10^{5}, 10^{6}$ and $10^{7}$ spores/ $\mathrm{ml}$ and applied as poisonous suspension for 5,7 and 10 days.

Increased mortality percentages were obtained for the three agents chosen, at ${ }^{7} 10$ spores / $\mathrm{ml}$, being $92.4,80.8$ and $76.0 \%$, respectively after 10 days. Calculated $\mathrm{LC}_{50}$ after $72 \mathrm{hr}$. were $1.4 \times 10^{2}$, $4.6 \times 10^{2}$ and $2.4 \times 10^{3}$ spores $/ \mathrm{ml}$, respectively. A new insect spores bait trap was designed for field experiments, and applied in the field trails in Ibshway district, Fayoum Governorate, Egypt on apple tress Malus pumila. In such trails, double concentrations of the aforementioned once were used. Higher percentages of mortality were obtained from April to September. Reduction percentages of 93.2, 85.0 and $84.9 \%$ at the concentration $2 \times 10^{7}$ spores $/ \mathrm{ml}$ for $M$. anisopliae, $V$. lecanii and B. bassiana, respectively.
\end{abstract}

Key words: Ceratitis capitata Metarhisium anisopliae, Beauveria bassinet, INTRODUCTION Verticillium lecanii, entomopathogen, Bioinsecticides, Bait trap.

Ceratitis capitata (Wiedemann) is well known as dangerous highly polyphagous pest against many fruitful crops all over the world (Garcia-Mari 2008). The damages caused by Medflies result first from oviposition in fruits followed by larvae feeding in addition to decomposition of plant tissue by invading secondary micro-organisms. Larval feeding damage in fruits is the most important. Mature attacked fruits may develop a water soaked appearance. Young fruits become distorted and usually drop. The larval tunnels provide entry points for bacteria and fungi that cause the fruit to rot (Bachrouch et al., 2008). In addition Ceratitis capitata which is thought to have originated in Africa. It is well adapted to diverse climates and has in excess of 350 host fruit species (Layne and Bassi 2008), and were shown to transmit E. coli to wounded fruit apples (Bailey et al 2006), Therefore, the present study was carried out in Fayoum Governorate, to Egypt, 2010, to evaluate the spores trap capacity in monitoring and controlling the $C$. capitata on mango trees where the female seek suitable sites for oviposition and puncture mango fruit early in the season, before the fruit has rinened, forming great damage (Rohde et al., 2010). Metarhizium anisopliae,Beauveria bassiana and Verticillium lecanii were applied as spore's of suspensions. Evaluation the efficiency of the chosen entomopathogens was made in the laboratory as well as in the field.

Fayoum J. Agric. Res. \& Dev., Vol. 26, No.2, July, 2012 
MATERIALS AND METHODS

\section{A-Laboratory studies}

\section{Stock culture of $C$. capitata}

Adults of the this insect pest were collected from heavily infested fruits of apple collected from orchards and transferred to the laboratory, and left on a sandy soil, in muslin cages $(25 \times 25 \times 25 \mathrm{~cm})$ till emergence (Manrakhan and Lux 2006). The experimental insect, were reared on fresh apple fruits for three generations.

\section{Preparation of spore bait;}

The entomopathogenic fungi $M$. anisopliae, V. lecanii and B. bassiana, were isolated from naturally infested dead pupae and adults of $C$. capitata. Serial dilutions of each of these fungi were prepared at the concentrations of $10^{5}, 10^{6}$ and $10^{7}$ spores $/ \mathrm{ml}$. Each was added to $1 \mathrm{ml}$ tween $40,20 \mathrm{ml}$ molasses and $1 \mathrm{ml}$ glycerin. (Castillo et al., 2000).

\section{Efficiency tests:}

Twenty five adults of $C$. capitata were exposed in a cage to each of the suspension tested which was applied in a glass of $60 \mathrm{ml}$ supplied with a wick for 5, 7 or10days. The insects were, then transferred to complete feeding on $10 \%$ sucrose solution. Four replicates were prepared for each concentration and for control which was given (10\% sucrose), only.

\section{Design of the spore bait trap:}

The spores bait trap is made of a yellow hard polypropylene, as lantern with four perforated sides for easy move of flies. The lantern is covered by an umbrella for shading and has one door for easy access of spore suspension glass, provided with a wick, was fixed on the base which was also perforated to allow the dead adults to pass down into a plastic bag connected a cylindrical tube inside the lantern. A ring and hanging wire were fixed on top of the trap for field use. Detailed of the design are shown in fig. No.1.

The same procedures were fallowed with any of each other pathogen.

\section{B. Field trials:}

In an apple orchard in Fayoum Governorate, district of Ibshway an area of about twelve kirrate $(2100) \mathrm{m}^{2}$. Three replicates as control were prepared per each concentration, as control, distributed randomly. Each replicate has five trees per concentration as control. In the control treatment a sticky yellow traps were used, double concentrations of the spores suspension of $M$. anisopliaee, $V$. lecanii and $B$. bassiana were prepared at the concentrations of $\left(2 \times 10^{5}, 2 \times 10^{6}\right.$ and $\left.2 \times 10^{7}\right)$ were applied per treatment. The experiments were carried out on apple trees and the biological spores bait traps were connected to an apple trees from April till the end of September, (Garcia-Mari, 2008).

The field trials were inspected weekly and the dead adults in the plastic pages of the spore bait traps were collected in paper pages, and transferred to the laboratory. Percent reduction of infestation was calculated.

The data were subjected to the (ANOVA) test and the L.S.D. 5\% was obtained The $\mathrm{LC}_{50 \mathrm{~s}}$ and reduction percentages for different treatments. 


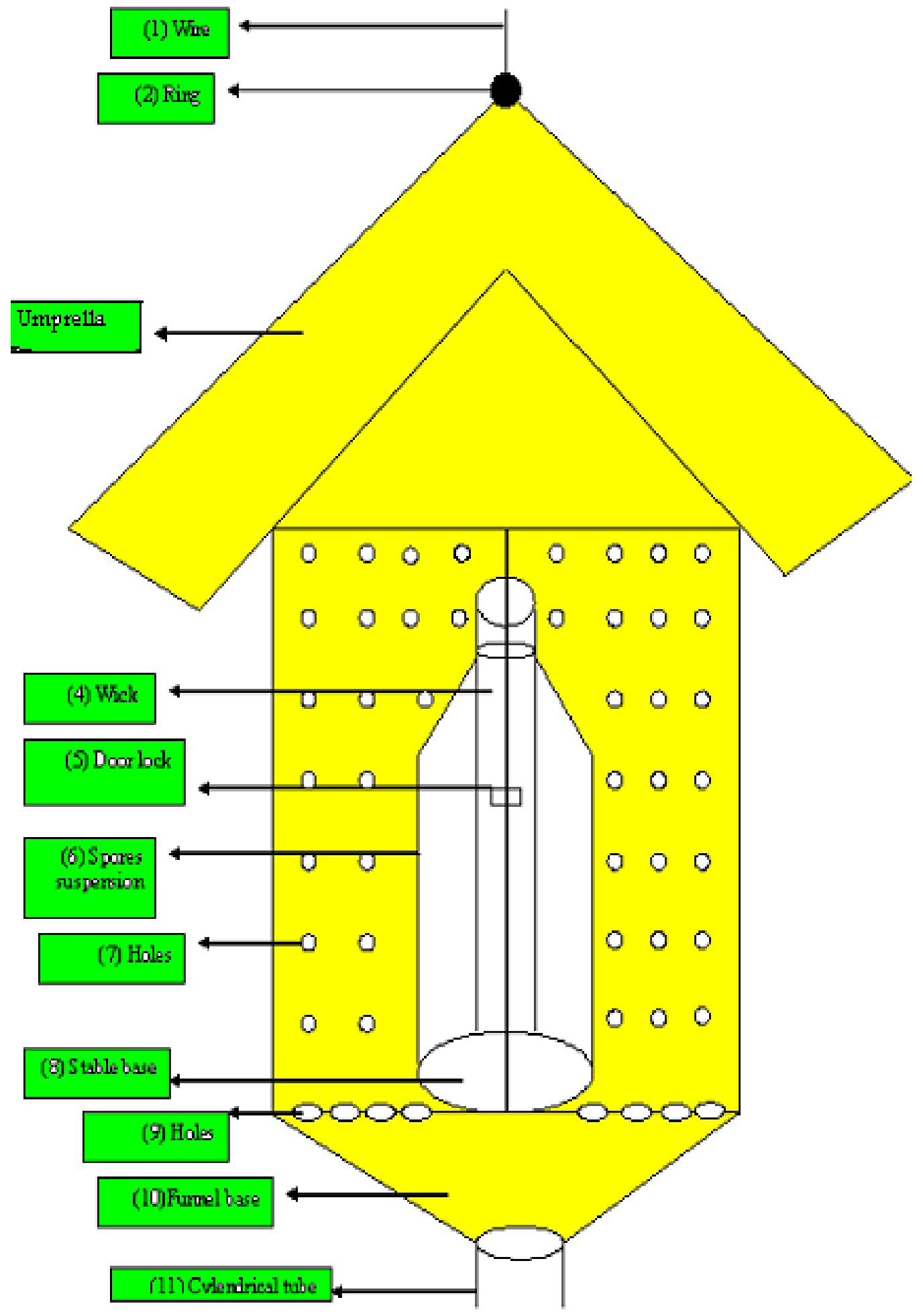

Fig (1): Design of the Insect Spores Bait Trap.

Fayoum J. Agric. Res. \& Dev., Vol. 26, No.2, July, 2012 


\section{RESULTS AND DISCUSSION}

For M.anisopliae, data in Table (1) and Figs (2,3 and 4) showed that the mortality percentages of $C$. capitata were 50.4, 55.6 and 69.2 and 58.4, 80.4 and 80.4and 80.0, 80.4 and $92.4 \%$ with the concentrations of $10^{5}, 10^{6}$, and $10^{7}$ spores/ $\mathrm{ml}$ of Metarhizium anisopliae after 5, 7 and 10 days, respectively, with no mortality in the check treatment.

For V. lecanii mortality percentages were $44.4,52.0$ and 60.8 and 55.2, 56.0 and 61.6 and $66.8,78.0$ and 80.8 with the concentrations of $10^{5}, 10^{6}$, and $10^{7}$ spores / $\mathrm{ml}$ after 5,7 and 10 days, respectively. and $0.0 \%$ in the check.

For B. bassiana, the mortality percentages were $41.6,50.0$ and 56.0 and $52.8,61.6$ and 61.6 and61.6, 74.0 and $76.0 \%$ with the concentrations of $10^{5}$, $10^{6}$, and $10^{7}$ spores $/ \mathrm{ml}$ after 5,7 and 10 days, respectively. and also $0.0 \%$ in the check, respectively.

The highest dead counts were found with $M$. anisopliae at the concentration of ${ }^{7} 10 \mathrm{spores} / \mathrm{ml}$. with a gradual increase over inspection period recording the highest value $92.4 \%$ after 10 days of treatment followed by $V$. lecanii value $80.8 \%$ while $B$. bassiana recorded the lowest reduction percentage which was $76.0 \%$. $\mathrm{LC}_{50}$ lowest values were after 10 days of treatment for M. anisopliae $\left(1.4 \mathrm{x}^{2} 10\right.$ spores $/ \mathrm{ml}$.) followed by $B$. bassiana, $\left(2.4 \mathrm{x}^{3} 10 \mathrm{spores} / \mathrm{ml}\right.$.) and $V$. lecanii $\left(2.7 \times 10^{3}\right.$ spores/ $\mathrm{ml}$.).

Statistical analysis of the showed significant differences in reducing $C$. capitata at different concentrations of the three entomopathogens after 5, 7 and 10 days.

This study revealed that the tested entomopathogenic fungi could be arranged according to their efficiency in the reduction of population density, of $C$. capitata in this descending order: $M$. anisopliae followed by $V$. lecanii and $B$. bassinet.

In this respect, (Ortiz-Urquiza et al., 2008) found that M. anisopliae isolate secretes a protein with insecticidal and antifeedant properties. The oral toxicity of this crude protein soluble extract was tested in a diet test against adults of $C$. capitata, which caused mortality which progressively increased with concentration and exposure time.

Fayoum J. Agric. Res. \& Dev., Vol. 26, No.2, July, 2012 
Table 1

Fayoum J. Agric. Res. \& Dev., Vol. 26, No.2, July, 2012 


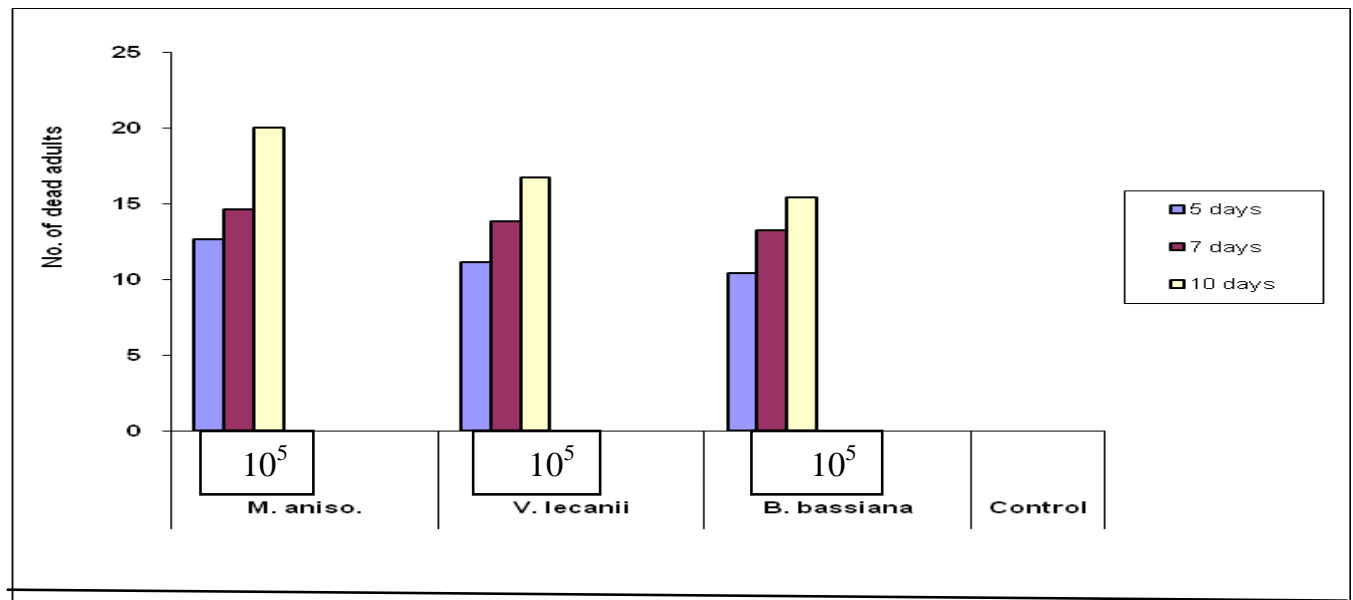

Fig (2): Efficiency of M. anisopliae V.lecanii and B. bassiana at the concentration of $10^{5}$ on C. capitata adults in the laboratory.

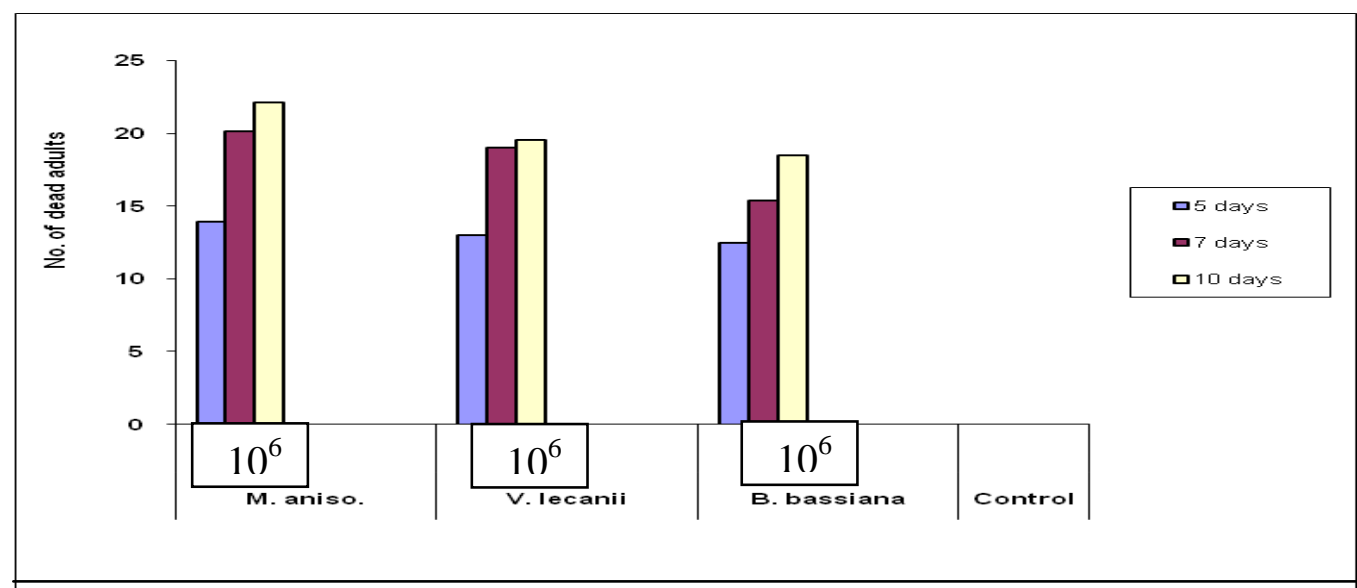

Fig (3): Efficiency of M. anisopliae, V. lecanii and B. bassiana at the concentration of $10^{6}$ on C. capitata adults in the laboratory.

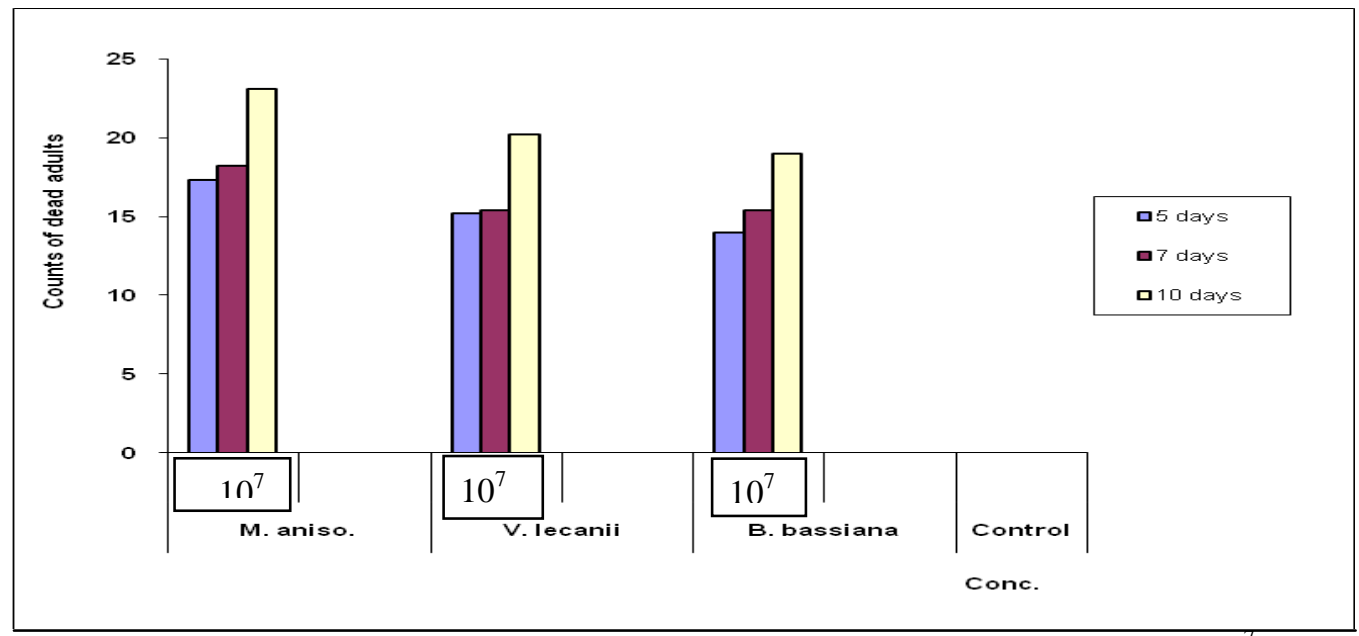

Fig (4): Efficiency of M. anisopliae,V.lecanii and B. bassiana at the concentration of $10^{\prime}$ on $C$. capitata adults in the laboratory.

Fayoum J. Agric. Res. \& Dev., Vol. 26, No.2, July, 2012 
A BIOLOGICAL SPORES BAIT TRAP TECHNIQUE AS A NEW..... 90

Table 2

Fayoum J. Agric. Res. \& Dev., Vol. 26, No.2, July, 2012 
Table 3

Fayoum J. Agric. Res. \& Dev., Vol. 26, No.2, July, 2012 
Table 3

Fayoum J. Agric. Res. \& Dev., Vol. 26, No.2, July, 2012 


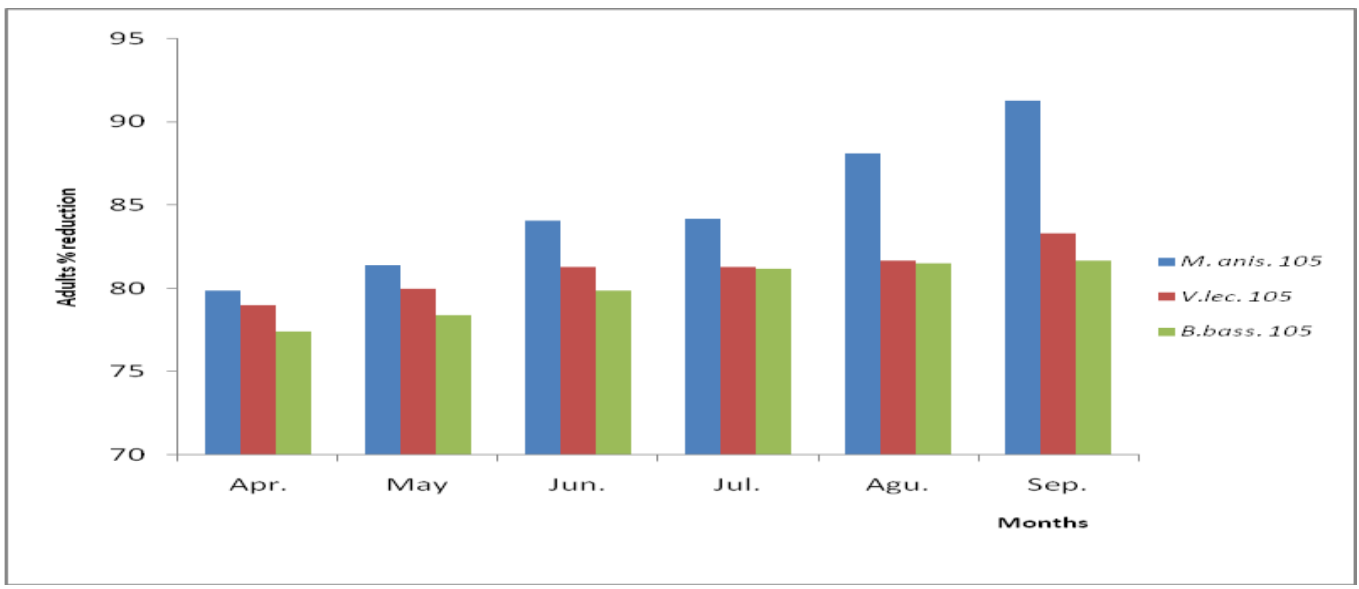

Fig (5): Monthly\% reduction of $C$. capitata adults attracted to spore bait traps of $M$. anisopliae, V. lecanii and B. bassiana at the concentration of $10^{5}$.

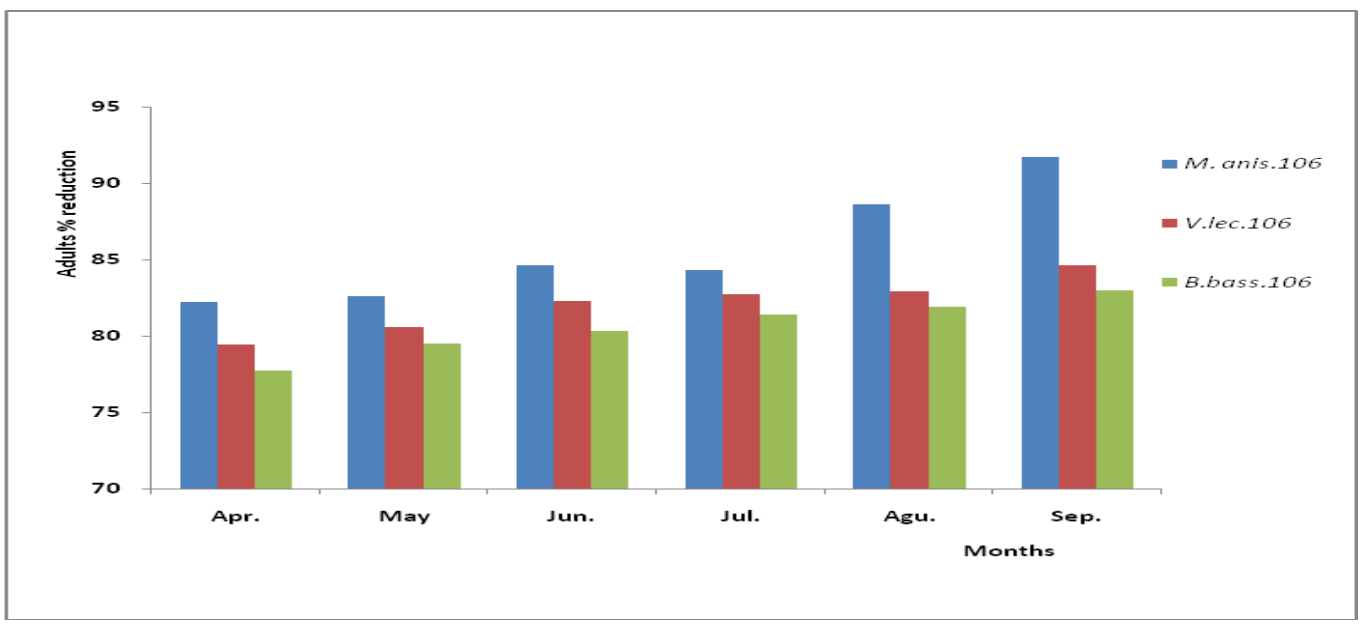

Fig (6): Monthly\% reduction of $C$. capitata adults attracted to spore bait traps of $M$. anisopliae, V. lecanii and B. bassiana at the concentration of $10^{6}$.

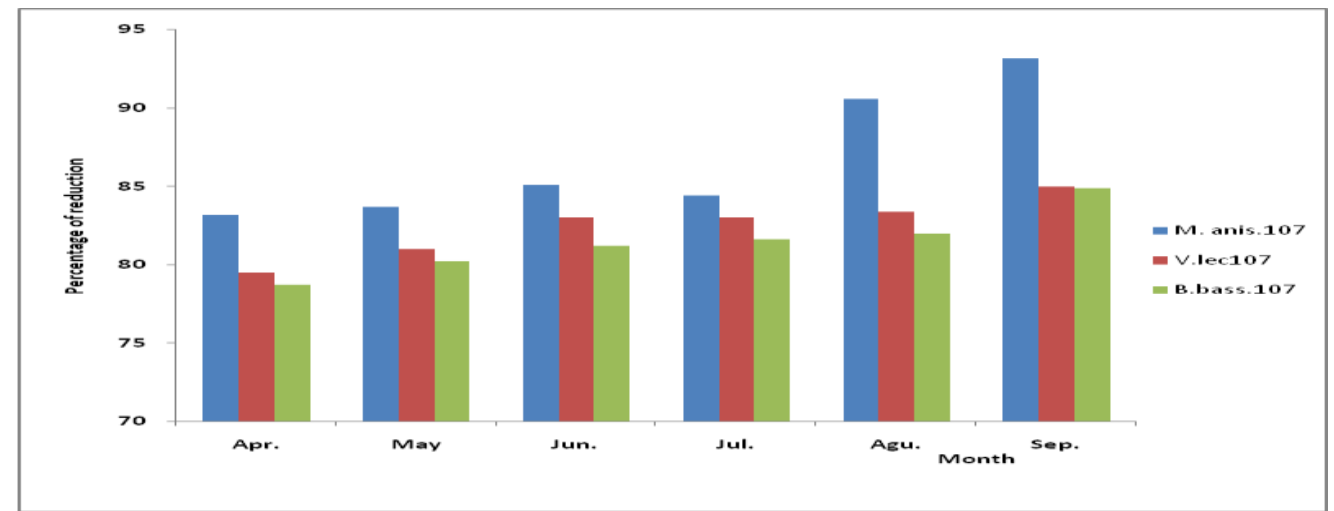

Fig (7): Monthly\% reduction of $C$. capitata adults attracted to spore bait traps of $M$. anisopliae, V. lecanii and B. bassiana at the concentration of $10^{7}$.

Fayoum J. Agric. Res. \& Dev., Vol. 26, No.2, July, 2012 
The same authors, 2010, reported, as new insecticide, a compound, which is the crude soluble protein extract from the fermentation product of the entomopathogenic fungus, $M$. anisopliae, a promising insecticide for the control of the Mediterranean fruit fly, C. capitata.

Konstantopoulou and Mazomenos (2005) revealed that moderate to high mortality rates for $C$. capitata adults occurred when the adults were exposed to conidia of $B$. bassiana causing $85.6 \%$ mortality. Dimbi et al., 2003 also found that $M$. anisopliae and $B$. bassiana were the most dominant pathogens on $C$. capitata where $M$. anisopliae was determined to be highly virulent and caused mortality between 7 to $100 \%$ after 4 days.

Goble et al (2011) tested M. anisopliae and B. bassiana under laboratory conditions against the subterranean life stages of the citrus pests, $C$. rosa Karsch, C. capitata Wiedemann and Thaumatotibia leucotreta Meyrick. (Lepidoptera: Tortricidae), treatment with a concentration of $1 \times 10^{7}$ conidia ml, fungal isolates had a significantly greater effect on the adults of $C$. rosa and $C$. capitata than on the puparia of these two fruit fly species.

\section{REFERENCES}

Bailey, M.J.; Lilley, A.K.; Timms-Wilson, T.M.; Spencer-Phillips, P.T.N. (2006): Microbial Ecology of Aerial Plant Surfaces. CABI Publishing ISBN. 1-84593-061-4, 9781845930615

Bachrouch, O., Mediouni-Ben Jemâa, J., Alimi, E., Skillman, S., Kabadou, T., and Kerber, E. (2008): Efficacy of the Lufenuron Bait Station Technique to Control Mediterranean Fruit Fly (Medfly) Ceratitis capitata in Citrus Orchards in Northern Tunisia. Tunisian J. of Plant Prot. 35 Vol 3, 35-45.

Castillo, M.A.; Moya, P.; Hernandez, E.; Primo-Yufera, E. (2000): Susceptibility of Ceratitis capitata Wiedemann (Diptera: Tephritidae) to entomopathogenic fungi and their extracts. Biol. Cont. 19: 3, 274-282.

Dimbi, Susan; Maniania, Nguya K.; Lux, Slawomir A.; Ekesi, Sunday; Mueke, Jones K. (2003): Pathogenicity of Metarhizium anisopliae (Metsch.) Sorokin and Beauveria bassiana (Balsamo) Vuillemin, to three adult fruit fly species: Ceratitis capitata (Weidemann), C. rosa var.fasciventris. Mycopathologia. 156(4): 375-382

Garcia-Mari, F. (2008): Status of Mediterranean fruit fly, Ceratitis capitata Wied. (Diptera: Tephritidae), and its control in Turkey.IOBC/WPRS Bulletin. 2008. 38: 136-141.

Goble, T.A.; Dames, J.F.; Hill, M.P.; Moore, S.D. (2011): Investigation of native isolates of entomopathogenic fungi for the biological control of three citrus pests. Bio. Cont. Scie. and Techn. 21: 10, 1193-1211.

Konstantopoulou, M.A.; Mazomenos, B.E. (2005): Evaluation of Beauveria bassiana and B. brongniartii strains and four wild-type fungal species against adults of Bactrocera oleae and Ceratitis capitata. Bio. Cont. 50(2):293-305.

Fayoum J. Agric. Res. \& Dev., Vol. 26, No.2, July, 2012 
Layne, Desmond R.; Bassi, Daniele Peach (2008): The: Botany, Production and Uses. CABI Publishing ISBN. 978-1-84593-386-9 France.

Manrakhan, A; Lux, S.A. (2006): Contribution of natural food sources to reproductive behaviour, fecundity and longevity of Ceratitis cosyra, $C$. fasciventris and C. capitata (Diptera: Tephritidae).Bul. of. Ent. Res. 96(3):259-268.

Ortiz-Urquiza, A.; Garrido-Jurado, I.; Santiago-Alvarez, C.; QuesadaMoraga, E. (2008): Partial purification and characterization of an insecticidal and antifeedant protein produced by the entomopathogenic fungus Metarhizium anisopliae. IOBC/WPRS Bulletin. 31: 178-185.

Ortiz-Urquiza, A.; Vergara-Ortiz, A.; Santiago-Alvarez, C.; QuesadaMoraga, E. (2010): Insecticidal and sublethal reproductive effects of Metarhizium anisopliae culture supernatant protein extract on the Mediterranean fruit fly. J. of. Appl. Ent., 134: 7, 581-591.

Rohde, C.; Moino Junior, A.; Silva, M.A.T. da; Carvalho, F.D.; Ferreira, C.S. (2010): Influence of soil temperature and moisture on the infectivity of entomopathogenic nematodes (Rhabditida: Heterorhabditidae, Steinernematidae) against larvae of Ceratitis capitata (Wiedemann) (Diptera: Tephritidae). Neotropical Ent. 2010. 39: 4, 608-611.

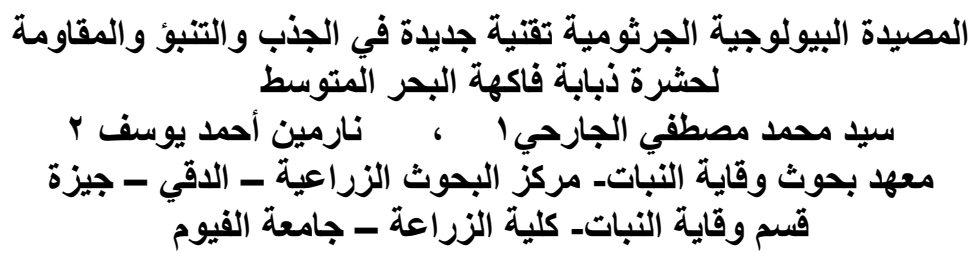

تهدف هذه الدراسة لمكافحة حشرة ذبابة البحر المتوسط Ceratitis capitata حيويا بإستخدام

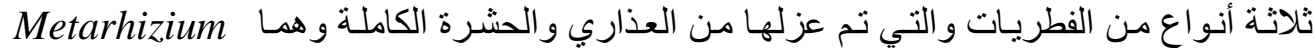

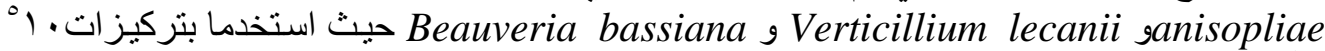

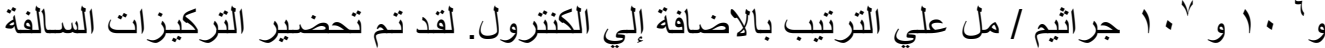

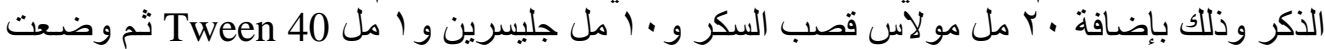

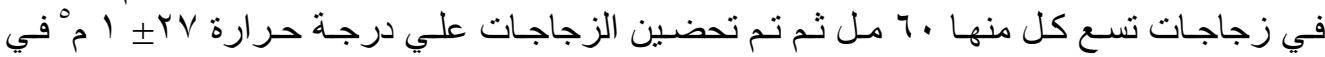

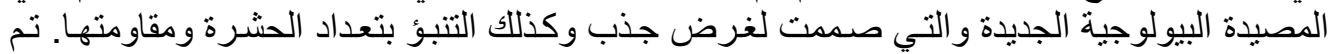

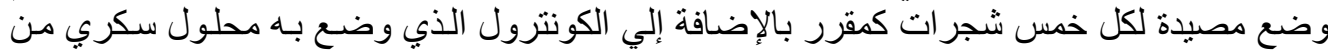

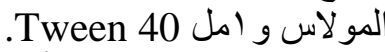

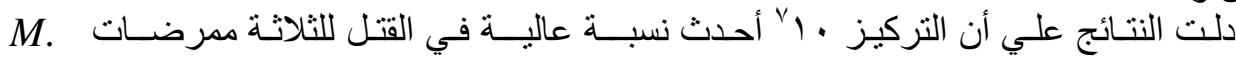
B. bassianag V. lecaniiganisopleiae

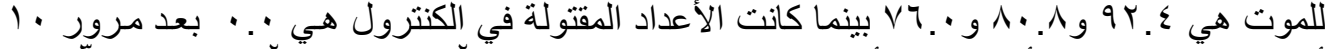

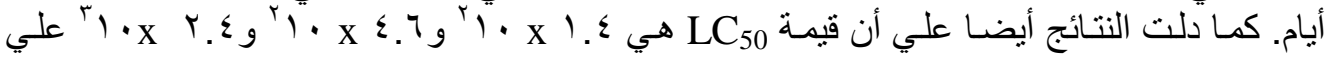
الترتيب

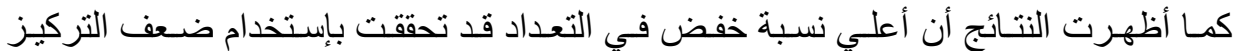

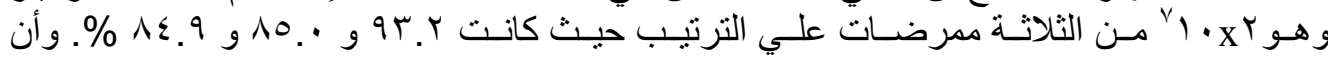

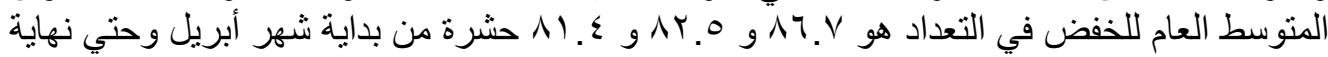
شهر سبتمبر.

Fayoum J. Agric. Res. \& Dev., Vol. 26, No.2, July, 2012 